\title{
Prediction of an assistance scenario adapted to learning styles of learners
}

\begin{abstract}
AMMOR Fatima-Zahra
Abstract - Assistance systems require a growing interest from a large community of researchers especially in the context of online learning, their main purpose is to provide a proactive or reactive support to accomplish a learning activity. The diversity of roles and skills required in tutoring (perception of behaviour, interaction analysis, increasing motivation and regulation rhythm, etc.) makes the task of tutor arduous and difficult to manage. Thus, the assistance of tutors is the main focus of several research offering assistance of answers in the form of learning situations models and support tools for the various tasks that the tutor must ensure to his learners. However, elementary and repetitive tasks of tutor are rarely taken into account specifically for their proactive character. Therefore, we propose to support learning scenario of learner by an assistance scenario suitable for his learning style, on the basis of a set of pre-defined assistance objects. The assistance of tutors allows then, on the one hand, to advise them on interventions that best respond to the need of learner, and on the other hand, to trigger an automatic assistance according to specific conditions, discharging the tutor automatable repetitive and arduous tasks.
\end{abstract}

Our contribution aims to relieve the tutor in his simple and monotonous tasks thanks to prediction method based on the Model of Assistance Object (MAO). The model aims to facilitate to tutor the definition of assistance objects more precisely. These assistance objects are used then by our prediction method to predict those most suitable depending on the learner's context, his learning style, and the feedback on the impact of objects of assistance which were previously presented.

Keywords - Assistance for online learning, tutors, learning styles, adaptation, assistance objects, prediction, IMS-LD.

\section{I- Introduction}

Tutoring is an essential and complementary function for teaching, especially in the context of elearning where we find many educational resources available for the transmission of knowledge, but many constraints to achieve tutoring interventions and help learners to stay motivated and carry out training. Thus, the tutor have to avoid the dropout of his learners by helping them to (1) Improve in their learning and succeed in their educational assessments, (2) Acquire some autonomy in
ELOMRI Amina

organizing their work, (3) Increase the level of confidence for their training and be more motivated to invest and (4) Be familiar with the technological tools and be able to adapt to new learning approaches. For this, the tutor is assigned a set of functions and provides a set of tutoring services [1][2][3] such as reception and orientation, technical support, evaluation, moderation of interactions, socio-emotional and motivational support, among others. In our work we are interested to four services, which include all of these roles and aim to help tutor to achieve his objectives, namely:

- Pedagogical service: helping learners to have better results in educational assessments with, for example, directing them to the appropriate resources and recalling the objectives of activities.

- Organizational service: improving the degree of autonomy in the organization of work by helping learners in the planning of training, in recalling the important dates, etc.

- Socio-emotional service: allowing tutors to encourage learner, value his work, inviting him to work in groups to stimulate his thinking, etc.

- Technique service: increasing the transparency of the apparatus for learners.

As we can see, each service attempts to satisfy a set of basic assistance purposes: guiding, recalling and motivating, etc. Each assistance goal may be represented by the tutoring interventions that depend on a particular context and a set of triggering conditions. In order to achieve the purpose of assistance "encouragement" for example, the tutor presents his tutoring intervention for some learning styles and when he noticed some fatigue coming from learner or a lack of concentration. Thus, it is interesting to mention that we cannot talk about tutorship interventions without speaking about contexts that they govern them. That is why we propose the term "object of assistance" to model any tutor response conditioned by its context of use.

In the context of our work, we propose a prediction method with aim to relieve the tutor by automating a set of repetitive tasks that can be used to assist learners suitably. For this to happen, our system is based on the manipulation of a set of assistance 
Proc. of the Second Intl. Conf. on Advances in Information Processing and Communication Technology - IPCT 2015

Copyright (c) Institute of Research Engineers and Doctors, USA .All rights reserved.

ISBN: 978-1-63248-044-6 doi: 10.15224/ 978-1-63248-044-6-25

objects, proposed by tutors and constructed through our model of assistance object. These assistance objects are then used by our system to predict those most appropriate according to the learner's context, his learning style and the feedback of their behaviours on the assistance objects previously presented to him during his apprenticeship.

Our paper is divided into three main parts. The first part presents our Model of Assistance Object (MAO) for definition of assistance objects by positioning it compared to the already existing models, this assistance object depend essentially on the learning styles of learners. The second part outlines the followed approach for prediction suitable assistance object by using the k-nearest neighbours algorithm. The last part presents a case study to illustrate the functioning of our prediction method of suitable assistance objects and the integration of this assistance object in IMS-LD learning scenario. We end with a conclusion and prospects.

\section{II- Model of Assistance Object MAO}

Defining assistance models has been already studied in the literature. In [4] for example, the authors present a descriptive model for determine tutoring strategies but does not take into account the triggers events and learner's characteristics. Also, [5] offers a rich generic model targeting a computerized system and linking between the various components necessary for establishment of a successful tutoring intervention. The standard IMS-LD [6] was also interested in assistance by integrating the concept of assistance activity in modelling of educational scenarios. However, even if the concept of role gives him a significant advantage for adaptability question, there is general in his description of the role and assistance activity.

In the context of our work, our main interested was the learning style of learners when we propose to deduct them implicitly by analyzing the interactions and adapt the assistance object. To achieve this, we propose to use the ANTClust classification algorithm [7] to derive the learning styles of learners from their traces of interaction [8].

Our assistance object allows to take into account several factors that integrate an assistance for specific learning scenario and model the context of its implementation like the events that will trigger adapted assistance object according to learning style of learner or specific type of learning activity, (etc.) what cannot be achieved using the existing models. For this, we offer our Model of Assistance Object (MAO) [9] to guide the tutor in the definition of a set of suitable assistance objects. Any assistance object is defined mainly by the learning style of the target learner and by the definition of the tutoring intervention. The tutor can specify the targeted learning style, as he can remain general in his definition and let our system to define the most appropriate assistance objects to our learning styles. Also, each tutoring intervention is represented by:

- Service: educational, organizational, socioemotional or technique services.

- Goal: the primary goal like: congratulate, encourage, etc.

- Type of activity: the assistance object could refer to a specific type of activity. We take into account tree types of activities: consultation, evaluation and production activity.

- Work Setting: the assistance takes into account the form of work followed by learners: individual or collective work.

- Temporality: punctual (depends on the context) or permanent (displayed continuously).

- Synchrony: the assistance provided is either synchronous (currently displayed to the learner), or asynchronous (assistance provided when learner is not connected).

- Modality: the assistance can be either reactive or proactive. In our work, we will focus on proactive interventions that can be launched when an indirect solicitation is observed. Proactive mode contains the initiating events and associated trigger conditions.

- The associated resources represent resources that enrich our intervention, defined by (1) The media: content that can display (or not) to the learner and (2) The media type: the associated resource can be an animation, text, a link, etc.

\section{III- Manipulating Object of Assistance for the Prediction of Appropriate Assistance}

To guide tutors in the definition of assistance objects facilitates the automation of some of their tasks. In this work we propose a system to handle all of these assistance objects in order to make predictions about the best assistance object to provide for a given learner. This prediction depends on two constraints: (1) the context of learner. Indeed, the adaptation of the assistance depends on the learning style of the learner, the initiated activity or its type and the trigger event and (2) scenario of assistance associated to learner. Indeed, 
Proc. of the Second Intl. Conf. on Advances in Information Processing and Communication Technology - IPCT 2015 Copyright (c) Institute of Research Engineers and Doctors, USA .All rights reserved.

ISBN: 978-1-63248-044-6 doi: 10.15224/ 978-1-63248-044-6-25

we consider that the choice of assistance objects depends greatly on the impact of the previous presented assistance objects. The choice of the most appropriate assistance object is achieved through the algorithm of k-nearest neighbour (k-NN). K-NN is a supervised classification algorithm for predicting the more appropriate class for a given input object, according to its neighbours in an exemplar database. This is a simple algorithm, widely used and gives good results [10][11].

\section{A. Preparation of Assistance Objects for Prediction of Appropriate Assistance}

In our work, examples are represented by all the assistance objects defined by the tutor. The definition of our assistance objects can be general or specific for one or some learning styles. Also, assistance object may depend on the learning activities or general for any activity type. The characteristics of the assistance object in the basis of examples are represented by the vector:

\section{Context $_{\text {Assistance Object }}=\{$ Work Setting, Events triggers\}}

Where the event trigger represent the events triggers that tutor need to observe. It represented by the couple $\left\{\left(\right.\right.$ Event $_{i}$, Triggering $\left._{i}\right) / \mathrm{i} \in\{1, \ldots, \mathrm{n}\}$ where:

- Event $_{i}$ : we consider the following events triggers $=\{$ a long inactivity, the beginning of an activity, the end of an activity, a long lost focus, long consultation, a time $\mathrm{t}$ past, weak connection duration, low connection rate, goal not achieved, resource type, level of knowledge

- Triggering $_{i}$ : may be 'false', when the event is not triggering. Or the value of the triggering when it is 'true' (true for the event trigger « the beginning of an activity», duration of the inactivity for the event trigger «a long inactivity», level of knowledge for the event trigger «level of knowledge», etc.).

The membership class of the assistance object is represented by the set:

\section{$\Omega_{\text {Class }}=\{$ Service, Goal, Temporality, Synchrony, Media, Media Type\}}

These assistance objects are then manipulated, used for the creation of assistance scenarios and evaluated to help the tutor assess his assistance objects. The assistance scenarios are the historical learners' tutorship interventions and models the assistance sequences for each learner (and then for each learning style).

The first step for predicting our assistance objects is the reduction of the number of assistance objects to manipulate. Indeed, for each student, the objects of assistance selected are those that concern the learning activity initiated by the learner, or those related to the type of activity initiated by the learner. Also, the chosen assistance objects are those related to the learning style of the learner. Then, the events that trigger each selected assistance object represents the conditions that trigger our assistance for this learner and for commencing our prediction process.

\section{B. Prediction Process of Adapted Assistance}

There is two possible scenarios when system detects one of the events triggers in the learner's behavior :

\section{1) Learner without assistance scenario}

When the learner has no history of interventions for learning scenario, the system chooses the closest assistance object from our reduced examples according to its context and this by comparing the vectors of Context Learner and $_{\text {Lea }}$ Context $_{\text {Assistance object }}$. The total similarity between the two vectors means that for every i, Context $_{\text {Learner }_{i}}=$ Context $_{\text {Assistance object }}{ }_{i}$.

Paralleled, total dissimilarity means that for every i, Context $_{\text {Learner }_{i}} \neq$ Context $_{\text {Assistance object }}{ }_{i}$. Thus, using the distance proposed by [12] for categorical data, we have:

$$
\begin{gathered}
\mathrm{d}\left(\text { Context }_{\text {Learner }}, \text { Context }_{\text {Assistance object }}\right)= \\
\sum_{i} d\left(\text { Context }_{\text {Learner }_{i}}, \text { Context }_{\text {Assistance } \text { Object }_{i}}\right)
\end{gathered}
$$

With

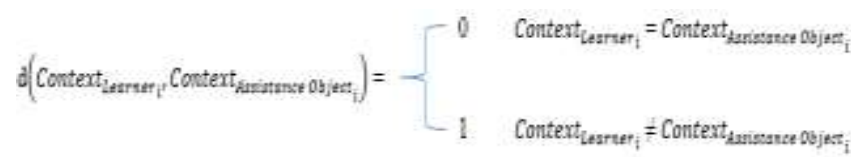

The nearest assistance object to the learner's context will be selected, and will be the starting point of the assistance scenario that will be associated to learner.

\section{2) Learner with assistance scenario}

When an assistance scenario is already associated to learner, the comparison is performed at all his assistance scenario. Thus, to provide an adapted assistance object to his context and his history, we compare his assistance scenario from existing assistance scenarios by following these steps:

- Step 1: choose the k-nearest objects of assistance to the context of learner, and belonging to existing assistance scenarios of the same learning style. The 
Proc. of the Second Intl. Conf. on Advances in Information Processing and Communication Technology - IPCT 2015

Copyright (C) Institute of Research Engineers and Doctors, USA .All rights reserved.

ISBN: 978-1-63248-044-6 doi: 10.15224/ 978-1-63248-044-6-25

value of $\mathrm{k}$ increases with the importance we want to give to the history of past interventions. Thus, increasing $\mathrm{k}$, we give the possibility to the algorithm to explore more assistance scenarios. However, this may impair the efficiency of the algorithm that can select assistance objects farther to the learner's context.

- Step 2: Gather all assistance scenarios containing these $\mathrm{k}$ objects of assistance.

- Step 3: Filter these assistance scenarios to keep only those that provide good results (evaluation presented later) and have the same number of assistance objects before the assistance object selected than the number of assistance objects in the history of the learner concerned. In case we end up with one or no assistance scenario, the nearest assistance object in Step 1 or present in the only chosen assistance scenario is presented, then go directly to the step 6

- Step 4: Compare the matrix learner with the assistance scenarios where the Learner Matrix represents the vectors of all assistance objects in the assistance scenario associated to the learner, and the Assistance Scenario Matrix represents the vectors of all assistance objects in the scenario chosen present before the assistance object selected in step 1. Thus, the Assistance Scenario matrix must have the same dimensions as the matrix learner. The comparison between the two matrices is done by simply recovering $\sum C_{i j}$ with $C_{i j}=$ $\mathrm{d}\left(\right.$ Matrix $_{\text {learner }_{i j}}$, Matrix $\left._{\text {AssSc }_{i j}}\right)$, where the both of the matrices have the same dimensions. Thus, the closest assistance scenario is represented by the one whose distance from the learner's assistance scenario is the smallest.

- Step 5: Select the nearest assistance scenario to the learner's assistance scenario, and then retrieve the assistance object associated with it.

- Step 6: associate assistance object to learner and enrich their assistance scenario.

Once the system choses an adequate assistance object and adds it to assistance scenario of learner, the previous assistance object presented and the assistance scenario are evaluated.

\section{3) Evaluation of the prediction made}

The evaluation of assistance scenarios is performed at the elementary level when the object is added or after each assessment activity conducted by the learner, and at the global level. The assessment at the elementary level is based on four evaluation indicators (table 1).
The evaluation is carried out by studying the curves after each addition of a new assistance object. To this end, the curve representing each indicator is measured from the time that the last object of assistance is presented and the newly added assistance object. The curve models a good evaluation when the value of the indicator shows an improvement or stagnation performance (increased connection rate, decreased the number of requests from support tools, etc.), bad evaluation otherwise. The assistance scenario is considered positively assessed if the number of positive feedback is greater than or equal to the number of negative evaluation.

TABLE 1: INDICATORS FOR EVALUATION OF THE GLOBAL ASSISTANCE SCENARIO

\begin{tabular}{|c|c|c|}
\hline & The aim of the indicator & Description \\
\hline $\begin{array}{c}\text { Gained } \\
\text { Confidence } \\
\text { Level }\end{array}$ & $\begin{array}{l}\text { Evaluate the effectiveness of } \\
\text { social-emotional assistance } \\
\text { service in our scenarios for } \\
\text { each learning style. Positive } \\
\text { evaluation means that the } \\
\text { assistance scenario happens } \\
\text { to motivate the learner in his } \\
\text { training. }\end{array}$ & $\begin{array}{l}\text { Calculated according } \\
\text { to (1) the frequency of } \\
\text { connections and (2) } \\
\text { the duration of their } \\
\text { connections. }\end{array}$ \\
\hline $\begin{array}{r}\text { Res } \\
\text { obtair } \\
\text { Educa } \\
\text { Asses }\end{array}$ & $\begin{array}{l}\text { Evaluate the effectiveness of } \\
\text { the pedagogical service in } \\
\text { our assistance scenario. } \\
\text { Positive evaluation means } \\
\text { that our assistance scenario } \\
\text { happens to accompany } \\
\text { learners in improving his } \\
\text { performance. }\end{array}$ & $\begin{array}{l}\text { The learner's } \\
\text { performance is } \\
\text { considered positive } \\
\text { when the grade is } \\
\text { positive (more than } \\
50 \% \text { correct), and } \\
\text { negative otherwise. }\end{array}$ \\
\hline $\begin{array}{c}\text { The } \\
\text { Apparatus } \\
\text { Transparency } \\
\text { Level }\end{array}$ & $\begin{array}{l}\text { Evaluate the effectiveness of } \\
\text { the technical service in our } \\
\text { assistance scenarios for } \\
\text { learning styles. } \\
\text { Positive evaluation means } \\
\text { that the assistance scenario } \\
\text { comes to help the learner and } \\
\text { support his technical } \\
\text { problems. }\end{array}$ & $\begin{array}{l}\text { According to (1) the } \\
\text { length of consultation } \\
\text { activities related to a } \\
\text { learning tool (we can } \\
\text { talk about videos, } \\
\text { sounds, software used, } \\
\text { etc.), and (2) the } \\
\text { number of requests } \\
\text { from support tools. }\end{array}$ \\
\hline $\begin{array}{l}\text { Degree of } \\
\text { Autonomy in } \\
\text { the } \\
\text { Organization } \\
\text { of Work }\end{array}$ & $\begin{array}{l}\text { Assess the effectiveness of } \\
\text { the organizational services in } \\
\text { assistance scenarios for our } \\
\text { learning styles and positive } \\
\text { evaluation for assistance } \\
\text { scenario means that learner is } \\
\text { more organized in his work. }\end{array}$ & $\begin{array}{l}\text { It is based on the } \\
\text { objectives achieved (1) } \\
\text { or not (-1) of the } \\
\text { learner. }\end{array}$ \\
\hline
\end{tabular}

The global evaluation of the degree of carry out of the learner's learning scenario is represented by the indicator "degree of drop out / carry out" and its objective is to infer the degree of carry out of the learner in his training. This indicator is calculated according to the four indicators seen above and is considered positive if at least, two of these indicators were evaluated positively, otherwise negative. Thus we can infer, by evaluating our assistance scenarios that such assistance scenario is more beneficial for learning style A than for B. Also as for learning style, we can deduce the most appropriate tutorship assistance for our learning styles: organizational services for example are more 
Proc. of the Second Intl. Conf. on Advances in Information Processing and Communication Technology - IPCT 2015

Copyright (c) Institute of Research Engineers and Doctors, USA .All rights reserved.

ISBN: 978-1-63248-044-6 doi: 10.15224/ 978-1-63248-044-6-25

effective for certain learning styles than socioemotional service, etc.

\section{IV- Implementation of our approach of prediction adapted assistance object}

When the tutor connects to the interface, he can define assistance objects belonging, or not to learning activities, which will subsequently be added to IMS-LD scenario (the choice fell on IMSLD for its ability to model assistance activities). Now, consider a dynamic learner $A_{1}$ that study the learning activity "Tables in Java". We present examples of some useful assistance objects for dynamic $A_{1}$ :

TABLE 2. DEFINITION OF ASSISTANCE OBJECTS ASSOCIATED WITH THE LEARNING SCENARIO

\begin{tabular}{|c|c|c|}
\hline 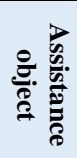 & Context of Assistance object & $\begin{array}{c}\text { Description of } \\
\text { Assistance object }\end{array}$ \\
\hline $\begin{array}{l}\stackrel{p}{0} \\
\stackrel{+}{\omega}\end{array}$ & $\begin{array}{l}\text { \{(Perfectionist, Rebellious, } \\
\text { Dynamic, Kind, Emotional), « } \\
\text { Tables in JAVA », Consultation, } \\
\text { Individual, (10, min), False, } \\
\text { False, False, False, False, False, } \\
\text { False, False, False, False }\}\end{array}$ & $\begin{array}{l}\text { \{Socio-emotional, } \\
\text { stimulate reflection } \\
\text { punctual, Synchronous } \\
\text { "According to what you } \\
\text { have done so far, what } \\
\text { do you think of ...", text }\end{array}$ \\
\hline$\stackrel{1}{0}$ & $\begin{array}{l}\text { \{(Kind, Emotional, Perfectionist, } \\
\text { Dynamic), all, Consultation, } \\
\text { Individual, False, true, False, } \\
\text { False, False, False, False, False, } \\
\text { False, False, False }\}\end{array}$ & $\begin{array}{l}\text { \{Socio-emotional, } \\
\text { Welcome, punctual } \\
\text { Synchronous, "Welcome } \\
\text {...", animation\} }\end{array}$ \\
\hline రి & $\begin{array}{l}\text { (Dynamic, Kind, Perfectionist, } \\
\text { Emotional), all, Consultation, } \\
\text { Individual, (20, min), False, } \\
\text { False, False, False, False, False, } \\
\text { False, False, False, False }\}\end{array}$ & $\begin{array}{l}\text { \{Socio-emotional, } \\
\text { encourage, punctual, } \\
\text { Synchronous, } \\
\text { «Courage! ... », Audio }\}\end{array}$ \\
\hline
\end{tabular}

Our assistance is carried out after the outbreak of one of the triggers associated with our five objects of assistance. Now consider that our learner knows inactivity for 10 minutes. The system is faced with two cases:

- The learner does not have an assistance scenario: in this case the system chooses in this case the closest assistance: OA43, and his assistance scenario is built. At this level, the assistance object selected is not evaluated. The roles concerned by the assistance object are presented in the global definition of assistance object in IMS-LD (figure $1)$.

- The learner has an assistance scenario:

- The system chooses the $\mathrm{k}$ nearest neighbors (we choose $\mathrm{k}=2$ ): OA43 and $\mathrm{OA} 2$
- The system compares the assistance scenario of the learner with the assistance scenarios containing the two chosen assistance objects. These scenarios should have the same number of assistance object before the selected objects of assistance than the assistance scenario of learner. The assistance scenarios are represented in IMS-LD as structures of activities which previously presented assistance objects are defined in a new category that we call "dependence-records".

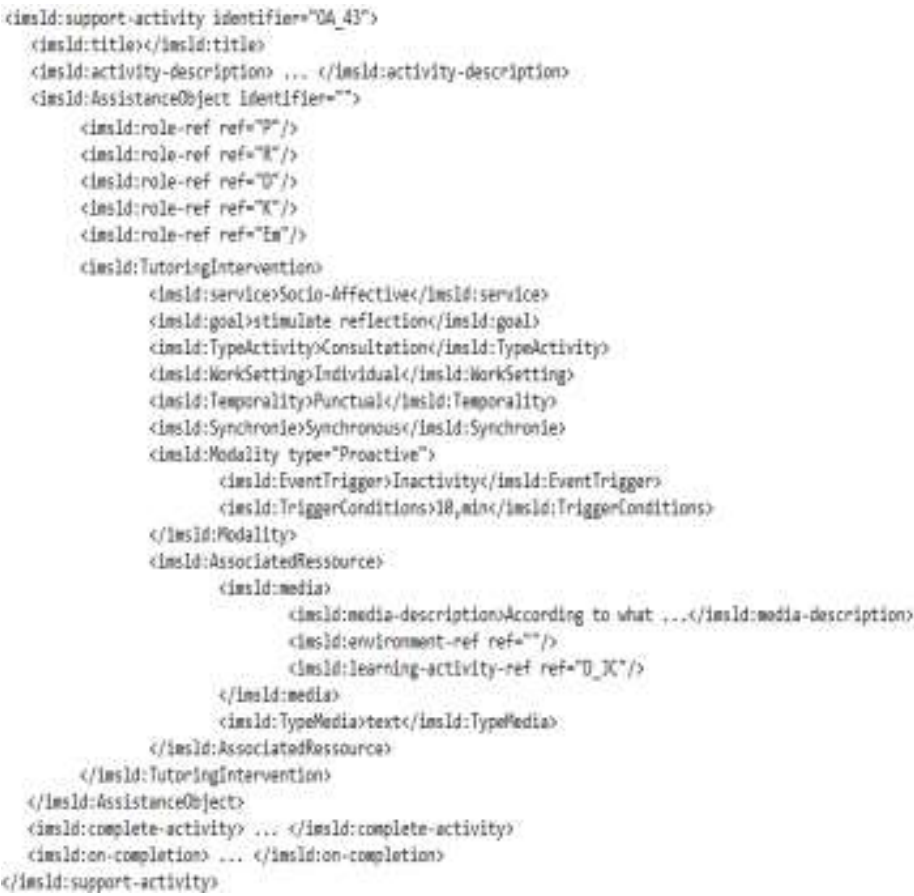

Figure 1: Definition of assistance object OA_43 
Proc. of the Second Intl. Conf. on Advances in Information Processing and Communication Technology - IPCT 2015

Copyright (C) Institute of Research Engineers and Doctors, USA .All rights reserved.

ISBN: 978-1-63248-044-6 doi: 10.15224/ 978-1-63248-044-6-25

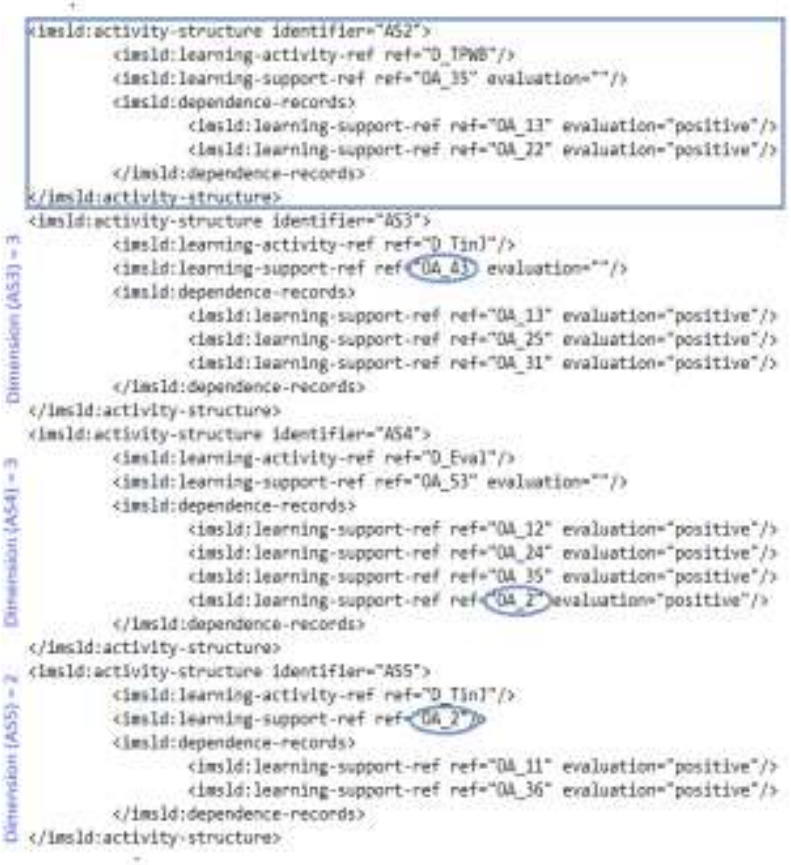

Figure 2: The existing assistance scenarios

The assistance scenario AS5 cannot be taken into account because it has not the same size - arriving to the chosen objects of assistance (in this case OA_2) - as the assistance scenario of learner (AS2). Comparison leads us to choose the assistance scenario AS3 and therefore the AO43 assistance will be selected and associated with learner assistance scenario. When the AO43 assistance object is added to the learner assistance scenario, the assessment phase begins. We assume in our case that our assistant objects are evaluated positively in all four indicators for AS3 (results indicator also obtained because the activity that precedes the activity "Tables in Java" is an evaluation activity). This brings us to confirm the positive assessment of the last presented assistance object (in this case OA_35) and our assistance scenario (in this case AS2). The local assessment of assistance objects is necessary to facilitate for tutor subsequently improve his assistance.

\section{Conclusion \& Perspectives}

The aim of our work is to support the work of the tutor in an online learning environment where it is difficult to be available at any time a learner connects. After defining the objects of assistance through our Model of Assistance Object (MAO), our prediction approach handles these objects and chooses the most suitable according to the learner's learning style, his context, and his scenario of assistance (if it exists). This makes it possible to provide assistance tailored to the learner and increase their motivation and interest in training. An implementation start was performed to test the functionality of our system. We aim eventually to implement our system in a real context to see directly its effectiveness on learners.

\section{References}

[1]. J.J. Quintin, «Accompagnement d'une formation asynchrone en groupe restreint: modalités d'intervention et modèles de tutorat », Sciences et Technologies de 1'Information et de la Communication pour l'Éducation et la Formation, Volume 15, 2008

[2]. J. Rodet, « Des fonctions et des plans de support à l'apprentissage à investir par les tuteurs à distance », Le blog de $\mathrm{t} @ \mathrm{~d}$, le portail du tutorat à distance : www.tutoratadistance.fr, consulté en 2013 : http://blogdetad.blogspot.com/2012/06/des-fonctionset-des-plans-de-support.html

[3]. E. Garrot, «Assistance au tuteur : prototype d'un système pour l'adaptation de situations d'apprentissage aux apprenants », Revue technique et science informatiques, vol $26 \mathrm{n}^{\circ} 6$ p. 723-750, 2007, Hermès-Lavoisier, Paris

[4]. P. Gounon, P. Leroux, « Modéliser l'organisation du tutorat pour assister la description de scénarios d'encadrement », Sciences et Technologies de 1'Information et de la Communication pour 1'Éducation et la Formation, Volume 16, 2009

[5]. A. Dufresne, J. Basque, G. Paquette, M. Léonard, K. Lundgren-Cayrol, S. Prom Tep, «Vers un modèle générique d'assistance aux acteurs du téléapprentissage », Sciences et Technologies de 1'Information et de la Communication pour 1'Éducation et la Formation, Volume 10, 2003

[6]. IMS-LD, IMS GLOBAL Learning Consortium, IMS Learning Design Specification, accessible via : http://www.imsglobal.org/learningdesign/ldv1p0/ims1 d_infov1p0.html\#1509506, 2003

[7]. N. Labroche, «Modélisation du système de reconnaissance chimique des fourmis pour le problème de la classification non-supervisée Application à la mesure d'audience sur internet », SST/EA 2101 - Laboratoire d'informatique, thèse soutenue à E.P.U. - Département Informatique - 64 Avenue Portalis - Site technopôle - TOURS, 2003.

[8]. F.Z. Ammor, D. Bouzidi, A. Elomri, "Construction of Deduction System of Learning Profile from Linguistic Profiling Rules", 2013 International Conference on Information and Education Technology, Bruxelles, Belgium, in press

[9]. F.Z. Ammor, D. Bouzidi, A. Elomri, "A Support Model for Tutoring to Facilitate and Automate Tutoring Interventions", ICMCS'14, the 4th International Conference on Multimedia Computing and Systems, Marrakesh, Morocco, 2014

[10]. I. Tayari Meftah, «Modélisation, détection et annotation des états émotionnels à l'aide d'un espace vectoriel multidimensionnel », thèse de doctorat, Université Nice Sophia Antipolis, 2013

[11]. Y.C. Chang-a, W.Y. Kao, C.P. Chu, C.H. Chiu, "A learning style classification mechanism for elearning", Computers \& Education, 53, 273-285, 2009

[12]. Z. Huang, "Extension to the k-means algorithm for clustering large data sets with categorical values", 1998

About Author (s):

Fatima-Zahra Ammor was born in Casablanca, Morocco in 1986, she is a Ph.D student at the Faculty of Sciences - University Hassan II in 
Proc. of the Second Intl. Conf. on Advances in Information Processing and Communication Technology - IPCT 2015

Copyright (c) Institute of Research Engineers and Doctors, USA .All rights reserved.

ISBN: 978-1-63248-044-6 doi: 10.15224/ 978-1-63248-044-6-25

Casablanca - Morocco since 2010, specialty Computer Science. She has a Master in the same Faculty specialty Internet and Computer Engineering and she wanted to continue in the same field for her particular interest to the new technology. Her research interests concern particularly the e-learning system.

Driss Bouzidi is an associate professor in Computer Sciences at ENSIAS, University Mohammed V, Rabat, Morocco. He received his $\mathrm{Ph} . \mathrm{D}$ degree in computer sciences from the same university in 2004. His research area focuses mainly on collaboration systems and e-learning. He has participated via many research papers in some national and international conferences, and published in the referred Journals. He has also made many contributions to several chapters in some international books related to e-learning. He has also participated in some e-learning projects (elearning Judicial Curriculum, EUMEDIS, among others). He was vice-chair of the international conference NGNS'09, and TCP chair of NGNS10, NGNS12, and ICEER13. He is a founding member of two research associations APRIMT and e-NGN

Amina Elomri is a professor of Higher Education in Computer Science at the Faculty of Sciences, University Hassan II Ain Chock, Casablanca, Morocco. Her main scientific interests concern the optimization, transport and the logistic problems. She is responsible of a research team in the same faculty entitled "Modeling and Optimization for Mobile Services". She has participated with more than 20 research papers in workshops and conferences and published journal articles. 